\title{
Rekomendasi Wisata Umbul dengan K-Means Clustering
}

\author{
Fajar Pamungkas ${ }^{1)}$; Didik Nugroho2); Yustina Retno Wahyu Utami ${ }^{3)}$ \\ 1)2)3) Program Studi Informatika STMIK Sinar Nusantara \\ Email : ${ }^{1)}$ fajarssin@gmail.com; ${ }^{2}$ masdidikhoho@sinus.ac.id; ${ }^{3)}$ yustina_retno@sinus.ac.id
}

\begin{abstract}
District Klaten has many springs that are used by people for many things; one of them used for tourist attractions is umbul tourism. It is difficult to use K-Means Clustering Method for determine umbul tourism according to classification and spread in district Klaten. K-Means Clustering is a method of grouping data by taking parameters of a number clusters, and partitioning data into clusters, based on similarities between data in one cluster and dissimilarities between different clusters, the center of the cluster is the average of the cluster member values it called as centroid. The results of this study are grouping the umbul truism which are divided into three clusters namely Enough, Good and The Best. The result of the data, there are 4 umbul tourisms in the first cluster is Beautiful category, namely Tirtomoyo, Buto, Pancuran, and Besuki. In the third cluster of umbul tourism has good category, namely Tirto Mulyani umbul, Gedaren, Sumber Nila, Manten, Sigedang, and Kajen. In the best category in the second cluster has 8 umbul tourisms, namely Nila umbul, Tirto Mulyono, Ingas, Lumban Tirto, Ponggok, Tirto Raharjo, Jolotundo, and Tirtomulyono.
\end{abstract}

Keywords: K-Means Clustering, Umbul, Umbul Category, Tourist Destination

\section{PENDAHULUAN}

Kabupaten Klaten terletak di lereng Gunung Merapi yang merupakan salah satu gunung berapi paling aktif di Indonesia. Hal ini menjadikan berkah tersendiri bagi warga lainnya karena ternyata beberapa tempat di Kabupaten Klaten terdapat umbul atau sumber mata air yang deras dan jernih. Sumber air ini dapat dimanfaatkan warga masyarakat untuk kebutuhan sehari-hari, pengairan sawah, kolam ikan, pemancingan, dan objek wisata air atau biasa disebut dengan objek wisata umbul. Beberapa objek wisata umbul yang ada di Klaten antara lain Umbul Ponggok, Umbul Manten, Umbul Pluneng, Cokro tulung, Jolotundo, Umbul Sigedang dan lain-lain.

Banyaknya objek wisata umbul di Klaten menjadikan masyarakat maupun pengunjung kesulitan dalam mendapatkan informasi kategori objek wisata umbul yang baik, sehingga perlu adanya sebuah pemetaan dan pengelompokan objek wisata umbul di Klaten. Saat ini kota Klaten belum memiliki sistem untuk mengelompokan objek wisata umbul, maka dari itu untuk mengelompokan objek wisata tersebut penulis menggunakan Algoritma K-Means Clustering. Cluster akan dibagi menjadi tiga Cukup, Baik, dan Sangat Baik, hal ini dilakukan agar pengunjung dan masyarakat dapat mengetahui seberapa baik dan layak objek wisata umbul Klaten

K-Means adalah metode pengelompokan data dengan mengambil parameter sejumlah cluster, dan mempartisi data kedalam cluster tersebut, dengan berpatokan pada kemiripan antar data dalam satu cluster dan ketidakmiripan di antar cluster yang berbeda, pusat dari cluster adalah rata-rata dari nilai anggota cluster yang disebut centroid. Selain itu algoritma K-Means Clustering dinilai memiliki teknik yang sangat cepat dalam proses clustering untuk pengelompokan objek wisata umbul Klaten [1].

\section{TINJAUAN PUSTAKA}

\subsection{Penelitian Terkait}

Berikut tiga jurnal penelitian terdahulu yang terkait dengan pengelompokkan data mengunakan metode K-Means Clustering:

1. Penelitian yang dilakukan oleh Hartatik, STMIK Amikom Yogyakarta pada tahun 2014 dengan studi Pengelompokkan Mahasiswa Berdasarkan Nilai Ujian Nasional dan Ipk Menggunakan Metode $K$-means. Dalam penelitian ini penulis menggunakan 2 keriteria yaitu nilai Tes Seleksi dan nilai UN yang berfungsi sebagai parameter. Dalam penentuan jumlah cluster, penulis menentukannya menjadi 3 Cluster. Kemudian data nilai 2 kriteria tersebut dimasukan kedalam sistem dan dilakukan proses K-Means, kemudian di temukan hasil akhir berupa pola pengelompokan mahasiswa yang menunjukan bahwa mahasiswa yang 
masuk dengan nilai UN tidak selamanya memiliki Ipk terbaik [2].

2. Penelitian yang dilakukan oleh Nasari \& Darma, Universitas Potensi Utama tahun 2015 dengan studi Penerapan K-Means Clustering Pada Data Penerimaan Mahasiswa Baru. Dalam penelitian ini data yang akan diolah berjumlah 278 data. Penulis menggunakan 3 kriteria antara lain nilai UAN, asal sekolah dan prodi. Cluster yang ditentukan berjumlah 2 cluster. Setelah dilakukan perhitungan $K$ Means, disimpulkan bahwa siswa yang berasal dari sekolah SMA rata-rata memilih jurusan Sistem Informatika dan siswa yang berasal dari sekolah SMK rata-rata memilih jurusan Teknik Informatika [3].

3. Penelitian yang dilakukan oleh Febrizal Alfarasy Syam, STMIK Dharmapala Riau, tahun 2017 dengan studi Implementasi Metode Klastering K-Means Untuk Mengelompokan Hasil Evaluasi Mahasiswa. Penelitian ini dilakukan untuk memantau perkembangan kinerja akademik kedalam kategori yang sesuai dengan kinerja mahasiswa. Data yang akan diolah berjumlah 94 data. Jumlah cluster yang di tentukan adalah 4 cluster antara lain cluster mahasiswa berprestasi, berpotensi berprestasi, berpotensi bermasalah dan cluster mahasiswa bermasalah. Kriteria yang dihunakan ada 3 yaitu IPK1, IPK2, dan rata-rata kehadiran. Setelah dilakukan perhitungan $K$-Means, dihasilkan pola pengelompokan sesuai kinerja mahasiswa, sehingga memudahkan pemantauan perkembangan kinerja akademik [4].

\subsection{K-Means Clustering}

Pengelompokan K-means merupakan metode analisis kelompok yang mengarah pada pemartisian $\mathrm{N}$ (objek pengamatan) ke dalam $K$ kelompok (cluster) dimana setiap objek pengamatan dimiliki oleh sebuah kelompok dengan mean (rata-rata) terdekat, dimana keduanya mencoba untuk menemukan pusat dari kelompok dalam data sebanyak iterasi perbaikan yang dilakukan oleh kedua algoritma [5].

K-Means Clustering pada dasarnya hanya mengambil sebagian dari banyaknya komponen yang didapat untuk kemudian dijadikan pusat cluster awal, pada penentuan pusat cluster ini ditentukan secara acak (random). Kemudian algoritma K-means akan menguji masing-masing dari setiap komponen dalam populasi data tersebut dengan persamaan euclidean distance dan menandai komponen tersebut ke dalam salah satu pusat cluster yang telah didefinisikan sebelumnya tergantung dari jarak minimum antar komponen dengan tiap-tiap pusat cluster. Selanjutnya menghitung centroid dari mean di setiap cluster, sehingga akan terbentuk cluster baru. [5]

Algoritma K-Means pada dasarnya melakukan 2 proses yakni proses pendeteksian lokasi pusat cluster dan proses pencarian anggota dari tiap-tiap cluster. Pusat cluster (centroid) awal yang digunakan untuk memulai proses clustering dengan metode $K$ Means ditentukan secara random. Untuk mengukur jarak antara pusat cluster di gunakan rumus Euclidean Distance dengan persamaan :

$$
d(x, y)=|x-y|=\sqrt{\sum_{i=1}^{n}\left(x_{i}-y_{i}\right)^{2}}
$$

\section{Dimana:}

$$
\begin{array}{ll}
\mathbf{x} & \text { : Titik data pertama } \\
\mathbf{y} & \text { : Titik data kedua } \\
\mathbf{n} & \text { : Jumlah karakteristik (attribut) }
\end{array}
$$

$\mathbf{d}(\mathbf{x}, \mathbf{y})$ : Euclidian distance yaitu jarak antara data pada titik $x$ dan titik $y$ menggunakan kalkulasi matematika

Parameter yang digunakan dalam penelitian ini adalah iterasi dalam proses perhitungan $K$-means dengan jarak terpendek dan memiliki anggota tetap atau perbedaan jarak antar centroid dengan iterasi sebelumnya. Untuk menghitung pusat cluster baru $\mathrm{V}_{\mathrm{ik}}$, digunakan rumus sebagai berikut :

$$
v_{i k}=\frac{\sum_{k=1}^{N_{1}} x_{i k}}{N_{i}}
$$

Nilai centroid baru $\left(\mathrm{V}_{\mathrm{ik}}\right)$ adalah jumlah data pada cluster ke-i dibagi jumlah data yang menjadi anggota cluster ke-i $\left(\mathrm{N}_{\mathrm{i}}\right)$ [6].

\section{METODE PENELITIAN}

Perancangan sistem pemetaan objek wisata umbul dilakukan dengan metode Waterfall dan metode pengumpulan data serta perancangan sistem.

\subsection{Metode Pengumpulan Data}

Tahap ini digunakan untuk mendapat informasi yang tepat dan akurat penulis berusaha menggunakan metode pengumpulan 
data yang sesuai dengan pokok permasalahan yang akan diteliti. Data diperoleh dari jenis data kualitatif dan kuantitatif. Sumber data berasal dari data primer dan data sekunder yang diperoleh dengan cara observasi, wawancara, dan pencatataan secara sistematis di Dinas Kebudayaan Pariwisata Pemuda dan Olahraga dan Objek Wisata Umbul Klaten.

\subsection{Metode Perancangan Sistem}

Pada tahap ini dibutuhkan metode yang dapat mendefinisikan data secara jelas. Tahapan-tahapan yang dilakukan untuk membuat aplikasi sebagai berikut.

1. Tahap analisis sistem

Tahapan analisis data dengan algoritma K-Mean clustering untuk rekomendasi objek wisata ini adalah:

1) Menentukan jenis-jenis kriteria yang akan digunakan dalam melakukan perhitungan K-Means, karena jenis kriteria akan menjadi persyaratan utama dalam menentukkan pemetaan objek wisata umbul.

2) Menentukan kategori / cluster yang akan digunakan dalam pengelompokan perhitungan K-Means Clustering.

3) Menghitung data kuesioner untuk penilaian tiap-tiap kriteria pada objek wisata, dimana hasil akhir nilai tersebut digunakan untuk proses perhitungan $K$ Means.

4) Membuat tabel kemunculan setiap nilai untuk kriteria dari setiap data objek wisata.

5) Melakukan proses perhitungan K-Means Clustering.

6) Kategori obyek wisata.

\section{Tahap desain sistem}

Tahap ini memberikan gambaran tentang apa yang akan dikerjakan dan bagaimana bentuk tampilannya. Tahap ini memenuhi semua kebutuhan pengguna sesuai dengan hasil yang dianalisa yaitu rancangan sistem pemetaan objek wisata umbul di Klaten, dan membantu mendefinisikan arsitektur sistem secara keseluruhan.

3. Tahap implementasi sistem

Implementasi sistem ini menerapkan perancangan sistem ke dalam sistem berbasis web dengan menggunakan PHP sebagai bahasa pemograman dan MySQL sebagai database.

\section{Tahap pengujian sistem}

Ada dua tahap pengujian yaitu pengujian fungsionalitas dan validasi. Pengujian fungsionalitas sistem dengan blackbox untuk mengetahui bila terjadi kesalahan atau kekurangan sehingga sistem yang dibuat dapat diperbaiki untuk menghasilkan sistem sesuai yang diharapkan. Pengujian validasi dengan cara membandingan sistem yang telah dibangun dengan $K$-means dibandingkan dengan aplikasi Microsoft excel untuk mengetahui tingkat akurasi aplikasi yang dibuat [7].

\section{HASIL DAN PEMBAHASAN}

4.1 Menentukan jenis kriteria

Kriteria diperoleh dari wawancara dan masukan terhadap pengunjung wisata. Ke-6 kriteria tersebut antara lain tingkat kebersihan wisata, ruang ganti, kamar mandi, penjaja makanan, akses jalan dan keamanan wisata. Ke-6 kriteria tersebut adalah hal yang paling sering dipertimbangkan / dipertanyakan saat menentukan kondisi untuk penilaian terhadap objek wisata umbul.

Setiap kriteria akan diberikan nilai 1-3, apabila 1 artinya Cukup, apabila 2 artinya Baik dan apabila 3 artinya Sangat Baik. kriteria tersebut adalah:

1. Kebersihan.

Kebersihan tempat wisata dinilai dari banyak sedikitnya sampah yang berserakan yang dapat mengganggu kenyamanan wisatawan.

2. Ruang ganti

Ruang ganti yang memadai juga berpengaruh terhadap baik tidaknya fasilitas tempat wisata umbul, karena tempat wisata umbul adalah wisata air yang mana kondisi dan jumlah ruang ganti yang memadai sangat diperlukan.

3. Kamar mandi

Kamar mandi merupakan fasilitas yang wajib ada di setiap tempat wisata, sehingga jumlah kamar mandi menentukan kriteria baik tidaknya fasilitas tempat wisata umbul.

4. Penjaja makanan

Penjaja makanan merupakan aktifitas jual beli makanan yang terdapat di tempat wisata, jumlah penjaja makanan menentukan kriteria baik tidaknya tempat wisata, karna setiap wisatawan akan sangat membutuhkan sesuatu untuk dimakan setelah puas bermain air. 
5. Akses jalan

Akses jalan dinilai dari kelayakan jalan dan luas jalan yang akan dilewati untuk menuju lokasi tempat wisata, karena dengan adanya akses jalan yang baik, mampu menampung jumlah pengunjung dalam partai besar misalkan dengan menggunakan bus pariwisata.

6. Keamanan

Tingkat keamanan wisata dinilai dari ada dan tidaknya loker penitipan barang yang ada ditempat wisata, karena dengan adanya loker penitipan barang maka keamanan barang bawaan akan lebih terjamin.

\subsection{Perhitungan K-Means}

Metode K-Means Clustering digunakan untuk mengelompokan suatu data dengan menentukan cluster yang nantinya akan di gunakan untuk sistem pemetaan objek wisata umbul Klaten. Ada 18 Data umbul yang akan di hitung dengan K-Means sesuai dengan kriteria masing-masing. Data umbul ditunjukkan pada Tabel 1.

\section{Tabel 1. Data Umbul}

\begin{tabular}{|c|c|c|c|c|c|c|c|}
\hline No & Nama & kbrsihan & $\begin{array}{c}\text { Ruang } \\
\text { ganti }\end{array}$ & $\begin{array}{c}\mathrm{Kmr} \\
\text { mandi }\end{array}$ & $\begin{array}{c}\text { Penj } \\
\text { makanan }\end{array}$ & $\begin{array}{l}\text { Akses } \\
\text { jalan }\end{array}$ & $\begin{array}{c}\text { Kama } \\
\text { nan } \\
\text { wisata }\end{array}$ \\
\hline 1 & $\begin{array}{l}\text { Umbul } \\
\text { Tirtomoyo }\end{array}$ & 1 & 1 & 1 & 1 & 1.3 & 1.2 \\
\hline 2 & $\begin{array}{l}\text { Umbul } \\
\text { Buto }\end{array}$ & 1 & 1 & 1 & 1 & 2.3 & 1.2 \\
\hline 3 & $\begin{array}{l}\text { Umbul } \\
\text { Nila }\end{array}$ & 2.3 & 1.8 & 2.8 & 2.6 & 2.3 & 1.7 \\
\hline 4 & $\begin{array}{l}\text { Umbul } \\
\text { Tirto } \\
\text { Mulyono }\end{array}$ & 2.8 & 2.3 & 2.8 & 2.2 & 2.9 & 2.1 \\
\hline 5 & $\begin{array}{l}\text { Umbul } \\
\text { Tirto } \\
\text { Mulyani }\end{array}$ & 2.2 & 1.3 & 1.7 & 2.2 & 2.6 & 1.9 \\
\hline 6 & $\begin{array}{l}\text { Umbul } \\
\text { Gedaren }\end{array}$ & 2.7 & 1.1 & 1.1 & 2.7 & 3 & 1.6 \\
\hline 7 & $\begin{array}{l}\text { Umbul } \\
\text { Ingas }\end{array}$ & 2.2 & 2.1 & 2.8 & 3 & 3 & 2.1 \\
\hline 8 & $\begin{array}{l}\text { Umbul } \\
\text { Lumban }\end{array}$ & 2.7 & 2.8 & 2.1 & 2.8 & 3 & 2.2 \\
\hline 9 & $\begin{array}{l}\text { Umbul } \\
\text { Sumber } \\
\text { Nila }\end{array}$ & 2.4 & 1.8 & 1.8 & 1.4 & 1.7 & 1.7 \\
\hline 10 & $\begin{array}{l}\text { Umbul } \\
\text { Ponggok }\end{array}$ & 2.8 & 3 & 3 & 3 & 3 & 2.8 \\
\hline 11 & $\begin{array}{l}\text { Umbul } \\
\text { Tirto } \\
\text { Raharjo }\end{array}$ & 2.6 & 2.6 & 2.2 & 2.4 & 3 & 2.2 \\
\hline 12 & $\begin{array}{l}\text { Umbul } \\
\text { Manten }\end{array}$ & 2.3 & 1.4 & 1.9 & 2.4 & 2.9 & 2.3 \\
\hline 13 & $\begin{array}{l}\text { Umbul } \\
\text { Sigedang }\end{array}$ & 2.7 & 1.4 & 1.6 & 2.6 & 1.8 & 2 \\
\hline 14 & $\begin{array}{l}\text { Umbul } \\
\text { Jolotundo }\end{array}$ & 2.4 & 2.8 & 2.8 & 2.6 & 2.9 & 2.1 \\
\hline 15 & $\begin{array}{l}\text { Umbul } \\
\text { Her } \\
\text { Pancuran } \\
\text { Sidomulyo }\end{array}$ & 1.7 & 1 & 1.1 & 1.1 & 1.8 & 1.2 \\
\hline 16 & $\begin{array}{l}\text { Umbul } \\
\text { Besuki }\end{array}$ & 1.4 & 1 & 1 & 1 & 1.7 & 1.2 \\
\hline 17 & $\begin{array}{l}\text { Umbul } \\
\text { Susuhan }\end{array}$ & 2.7 & 2.9 & 3 & 2.3 & 3 & 2.7 \\
\hline 18 & $\begin{array}{l}\text { Umbul } \\
\text { Kajen }\end{array}$ & 2.6 & 1.3 & 1.3 & 1.4 & 1.3 & 1.2 \\
\hline
\end{tabular}

Pusat cluster (centroid) awal yang digunakan untuk memulai proses clustering dengan metode $K$-Means diperoleh dengan cara acak / random. Untuk mengukur jarak antara pusat cluster di gunakan rumus Euclidean Distance, kemudian akan di dapat nilai matriks jarak yaitu, C1, C2, dan C3. Rumus Euclidian Distance.

Berikut ini perhitungan untuk menentukan nilai cluster pada iterasi pertama dengan Centroid 1, Centroid 2, Centroid 3 berdasarkan rumus (1). Pusat cluster untuk perhitungan pertama sebagai berikut:

$$
\begin{aligned}
& \mathrm{C} 1=(1,1,1,1,1.3,1.2) \\
& \mathrm{C} 2=(1.7,1,1.1,1.1,1.8,1.2) \\
& \mathrm{C} 3=(2.6,1.3,1.3,1.4,1.3,1.2)
\end{aligned}
$$

\section{Jarak pusat cluster pertama}

$d_{1}=\sqrt{(1-1)^{2}+(1-1)^{2}+(1-1)^{2}+(1-1)^{2}+(1,3-1,3)^{2}+(1,2-1,2)^{2}}=0,000$ Jarak pusat cluster kedua

$d_{2}=\sqrt{(1-1,7)^{2}+(1-1)^{2}+(1-1,1)^{2}+(1-1,1)^{2}+(1,3-1,8)^{2}+(1,2-1,2)^{2}}=0,872$ Jarak pusat cluster ketiga

$d_{3}=\sqrt{(1-2,6)^{2}+(1-1,3)^{2}+(1-1,3)^{2}+(1-1,4)^{2}+(1,3-1,3)^{2}+(1,2-1,2)^{2}}=1,703$

Dari hasil perhitungan di atas maka dihasilkan nilai cluster 1 yaitu 0.000 cluster 2 yaitu 0.872 dan cluster ke 3 yaitu 1.703. Hasil

\begin{tabular}{|c|c|c|c|c|c|}
\hline NO & NAMA & $\begin{array}{c}\text { Cluster } \\
1\end{array}$ & $\begin{array}{c}\text { Cluster } \\
2\end{array}$ & $\begin{array}{c}\text { Cluster } \\
3\end{array}$ & $\begin{array}{c}\text { Jarak } \\
\text { Terpendek }\end{array}$ \\
\hline 1 & $\begin{array}{l}\text { Umbul } \\
\text { Tirtomoyo }\end{array}$ & 0.000 & 0.872 & 1.703 & 0.000 \\
\hline 2 & Umbul Buto & 1.000 & 0.872 & 1.975 & 0.872 \\
\hline 3 & Umbul Nila & 3.063 & 2.577 & 2.298 & 2.298 \\
\hline 4 & $\begin{array}{l}\text { Umbul Tirto } \\
\text { Mulyono }\end{array}$ & 3.603 & 3.003 & 2.702 & 2.702 \\
\hline 5 & $\begin{array}{l}\text { Umbul Tirto } \\
\text { Mulyani }\end{array}$ & 2.375 & 1.744 & 1.772 & 1.744 \\
\hline 6 & $\begin{array}{l}\text { Umbul } \\
\text { Gedaren }\end{array}$ & 2.975 & 2.274 & 2.198 & 2.198 \\
\hline 7 & Umbul Ingas & 3.686 & 3.195 & 3.051 & 3.051 \\
\hline 8 & $\begin{array}{l}\text { Umbul } \\
\text { Lumban Tirto }\end{array}$ & 3.804 & 3.251 & 2.958 & 2.958 \\
\hline 9 & Umb Sbr Nila & 1.952 & 1.404 & 0.975 & 0.975 \\
\hline 10 & $\begin{array}{l}\text { Umbul } \\
\text { Ponggok }\end{array}$ & 4.549 & 4.053 & 3.719 & 3.719 \\
\hline 11 & $\begin{array}{l}\text { Umbul Tirto } \\
\text { Raharjo }\end{array}$ & 3.523 & 2.951 & 2.718 & 2.718 \\
\hline 12 & $\begin{array}{l}\text { Umbul } \\
\text { Manten }\end{array}$ & 2.897 & 2.296 & 2.287 & 2.287 \\
\hline 13 & $\begin{array}{l}\text { Umbul } \\
\text { Sigedang }\end{array}$ & 2.619 & 2.074 & 1.562 & 1.562 \\
\hline 14 & $\begin{array}{l}\text { Umbul } \\
\text { Jolotundo }\end{array}$ & 3.791 & 3.300 & 3.058 & 3.058 \\
\hline 15 & $\begin{array}{l}\text { Umbul Her } \\
\text { Pancuran } \\
\text { Sidomulyo }\end{array}$ & 0.872 & 0.000 & 1.131 & 0.000 \\
\hline 16 & Umbul Besuki & 0.566 & 0.346 & 1.393 & 0.346 \\
\hline 17 & $\begin{array}{l}\text { Umbul } \\
\text { Susuhan }\end{array}$ & 4.163 & 3.654 & 3.378 & 3.378 \\
\hline 18 & Umbul Kajen & 1.703 & 1.131 & 0.000 & 0.000 \\
\hline
\end{tabular}
perhitungan di atas ditunjukan pada Tabel 2.

Tabel 2. Hasil perhitungan iterasi ke 1 
Setelah mendapatkan hasil dari perhitungan iterasi pertama pada tabel 1 . Hitung kembali titik pusat (centroid) pada masing-masing cluster dengan menggunakan perhitungan rata-rata yaitu total nilai dari data pada cluster $\mathrm{n}$ dimensi ke-k dibagi jumlah data dari cluster $\mathrm{n}$ dimensi ke-k. Berikut perhitungan untuk menentukan pusat cluster dari tabel 1 .

Cluster pertama ada 1 data:

$\mathrm{C} 1=\frac{\text { Jumlah nilai aribut } 1 \text { cluster } 1}{\text { Jumlah data anggota cluster } 1}=\frac{1}{1}=1$

$\mathrm{Cl}=\frac{\text { Jumlah nilai aribut } 2 \text { cluster } 1}{\text { Jumlah data anggota cluster } 1}=\frac{1}{1}=1$

$\mathrm{C} 1=\frac{\text { Jumlah nilai aribut } 3 \text { cluster } 1}{\text { Jumlah data anggota cluster } 1}=\frac{1}{1}=1$

$\mathrm{C} 1=\frac{\text { Jumlah nilai aribut } 4 \text { cluster } 1}{\text { Jumlah data anggota cluster } 1}=\frac{1}{1}=1$

$\mathrm{C} 1=\frac{\text { Jumlah nilai aribut } 5 \text { cluster } 1}{\text { Jumlah data anggota cluster } 1}=\frac{1,3}{1}=1,3$

$\mathrm{C} 1=\frac{\text { Jumlah nilai aribut } 6 \text { cluster } 1}{\text { Jumlah data anggota cluster } 1}=\frac{1,2}{1}=1,2$

Cluster ke dua ada 4 data:

$C_{2}=\frac{\text { Jumlah nilai atribut } 1 \text { cluster } 2}{\text { Jumlah data ang gota cluster } 2}=\frac{6,3}{4}=1,575$

$\mathrm{C} 2=\frac{\mathrm{Jum} \text { lah nilaiatribut } 2 \text { cluster } 2}{\mathrm{Jum} \text { lah data ang gota cluster } 2}=\frac{4,3}{4}=1,075$

$\mathrm{C} 2=\frac{\mathrm{Jum} \text { lah nilai atribut } 3 \text { cluster } 2}{\mathrm{Jum} \text { lahdata ang gota clus ter } 2}=\frac{4,8}{4}=1,2$

$\mathrm{C} 2=\frac{\mathrm{Jum} \text { lah nilai atribut } 4 \text { clus ter } 2}{\mathrm{Jum} \text { lah data ang gota clus ter } 2}=\frac{5,3}{4}=1,325$

$C 2=\frac{\text { Jumlah nilaiatribut } 5 \text { cluster } 2}{\text { Jumlah data angg ota clv ster } 2}=\frac{8,4}{4}=2,1$

$\mathrm{C} 2=\frac{\mathrm{Jum} \text { lah nilai a tribut } 6 \text { clus ter } 2}{\mathrm{Jum} \text { lah data ang g ota cluster } 2}=\frac{5,5}{4}=1,375$
Cluster ke tiga ada 13 data:

$\mathrm{C} 3=\frac{\text { Jumlah nilai atribut } 1 \text { cluster } 3}{\text { Jumlah data anggota cluster } 3}=\frac{33,2}{13}=2,553$

$\mathrm{C} 3=\frac{\text { Jumlah nilai atribut } 2 \text { cluster } 3}{\text { Jumlah data anggota cluster } 3}=\frac{27,3}{13}=2,1$

C3 $=\frac{\text { Jumlah nilai atribut } 3 \text { cluster } 3}{\text { Jumlah data anggota cluster 3 }}=\frac{29,2}{13}=2,246$

$\mathrm{C} 3=\frac{\text { Jumlah nilai atribut } 4 \text { cluster } 3}{\text { Jumlah data anggota cluster } 3}=\frac{31,4}{13}=2,415$

$\mathrm{C} 3=\frac{\text { Jumlah nilai atribut } 5 \text { cluster } 3}{\text { Jumlah data anggota cluster } 3}=\frac{33,8}{13}=2,6$

$\mathrm{C} 3=\frac{\text { Jumlah nilai atribut } 6 \text { cluster } 3}{\text { Jumlah data anggota cluster } 3}=\frac{26,7}{13}=2,053$

Setelah pusat cluster (centroid) ke 2 di tentukan, ulangi perhitungan untuk menentukan nilai cluster pada tiap data untuk menghasilkan nilai pada Iterasi ke 2. Iterasi ke 2 ditunjukkan pada Tabel 3.

Tabel 3. Hasil iterasi ke 2

\begin{tabular}{|c|c|c|c|c|c|}
\hline NO & NAMA & $\begin{array}{c}\text { Cluster } \\
1\end{array}$ & $\begin{array}{c}\text { Cluster } \\
2\end{array}$ & $\begin{array}{c}\text { Cluster } \\
3\end{array}$ & $\begin{array}{c}\text { Jarak } \\
\text { Terpendek }\end{array}$ \\
\hline 1 & $\begin{array}{l}\text { Umbul } \\
\text { Tirtomoyo }\end{array}$ & 0.000 & 1.074 & 3.098 & 0.000 \\
\hline 2 & Umbul Buto & 1.000 & 0.743 & 2.828 & 0.743 \\
\hline 3 & Umbul Nila & 3.063 & 2.320 & 0.843 & 0.843 \\
\hline 4 & $\begin{array}{l}\text { Umbul Tirto } \\
\text { Mulyono }\end{array}$ & 3.603 & 2.737 & 0.739 & 0.739 \\
\hline 5 & $\begin{array}{l}\text { Umbul Tirto } \\
\text { Mulyani }\end{array}$ & 2.375 & 1.408 & 1.065 & 1.065 \\
\hline 6 & $\begin{array}{l}\text { Umbul } \\
\text { Gedaren }\end{array}$ & 2.975 & 2.007 & 1.668 & 1.668 \\
\hline 7 & Umbul Ingas & 3.686 & 2.854 & 0.967 & 0.967 \\
\hline 8 & $\begin{array}{l}\text { Umbul } \\
\text { Lumban Tirto }\end{array}$ & 3.804 & 2.953 & 0.928 & 0.928 \\
\hline 9 & $\begin{array}{l}\text { Umbul } \\
\text { Sumber Nila }\end{array}$ & 1.952 & 1.356 & 1.510 & 1.356 \\
\hline 10 & $\begin{array}{l}\text { Umbul } \\
\text { Ponggok }\end{array}$ & 4.549 & 3.754 & 1.580 & 1.580 \\
\hline 11 & $\begin{array}{l}\text { Umbul Tirto } \\
\text { Raharjo }\end{array}$ & 3.523 & 2.650 & 0.660 & 0.660 \\
\hline 12 & Umbul Manten & 2.897 & 1.942 & 0.908 & 0.908 \\
\hline 13 & $\begin{array}{l}\text { Umbul } \\
\text { Sigedang }\end{array}$ & 2.619 & 1.907 & 1.267 & 1.267 \\
\hline 14 & $\begin{array}{l}\text { Umbul } \\
\text { Jolotundo }\end{array}$ & 3.791 & 3.001 & 0.973 & 0.973 \\
\hline 15 & $\begin{array}{l}\text { Umbul Her } \\
\text { Pancuran } \\
\text { Sidomulyo }\end{array}$ & 0.872 & 0.450 & 2.520 & 0.450 \\
\hline 16 & Umbul Besuki & 0.566 & 0.610 & 2.763 & 0.566 \\
\hline 17 & $\begin{array}{l}\text { Umbul } \\
\text { Susuhan }\end{array}$ & 4.163 & 3.369 & 1.349 & 1.349 \\
\hline 18 & Umbul Kajen & 1.703 & 1.337 & 2.233 & 1.337 \\
\hline
\end{tabular}

Proses iterasi akan terus berulang hingga posisi data sudah tidak mengalami perubahan. Hasil pengelompokkan iterasi dibandingkan dengan hasil sebelumnya dan pada perhitungan ini berhenti pada iterasi 8 . 
Hasil iterasi ke 8 ditunjukan pada Tabel 4.

Tabel 4. Hasil iterasi ke-8

\begin{tabular}{|c|l|c|c|c|c|}
\hline NO & \multicolumn{1}{|c|}{ NAMA } & $\begin{array}{c}\text { Cluster } \\
\mathbf{1}\end{array}$ & $\begin{array}{c}\text { Cluster } \\
\mathbf{2}\end{array}$ & $\begin{array}{c}\text { Cluster } \\
\mathbf{3}\end{array}$ & $\begin{array}{c}\text { Jarak } \\
\text { Terpendek }\end{array}$ \\
\hline 1 & $\begin{array}{l}\text { Umbul } \\
\text { Tirtomoyo }\end{array}$ & 0.550 & 2.257 & 3.722 & 0.550 \\
\hline 2 & Umbul Buto & 0.594 & 2.065 & 3.417 & 0.594 \\
\hline 3 & Umbul Nila & 2.801 & 1.406 & 1.122 & 1.122 \\
\hline 4 & $\begin{array}{l}\text { Umbul Tirto } \\
\text { Mulyono }\end{array}$ & 3.259 & 1.742 & 0.561 & 0.561 \\
\hline 5 & $\begin{array}{l}\text { Umbul Tirto } \\
\text { Mulyani }\end{array}$ & 1.988 & 0.522 & 1.733 & 0.522 \\
\hline 6 & $\begin{array}{l}\text { Umbul } \\
\text { Gedaren }\end{array}$ & 2.552 & 1.154 & 2.243 & 1.154 \\
\hline 7 & $\begin{array}{l}\text { Umbul } \\
\text { Ingas }\end{array}$ & 3.380 & 1.900 & 0.719 & 0.719 \\
\hline 8 & $\begin{array}{l}\text { Umbul } \\
\text { Lumban } \\
\text { Tirto }\end{array}$ & 3.475 & 1.895 & 0.694 & 0.694 \\
\hline 9 & $\begin{array}{l}\text { Umbul } \\
\text { Sumber } \\
\text { Nila }\end{array}$ & 1.704 & 1.011 & 2.128 & 1.011 \\
\hline 10 & $\begin{array}{l}\text { Umbul } \\
\text { Ponggok }\end{array}$ & 4.265 & 2.683 & 0.920 & 0.920 \\
\hline 11 & $\begin{array}{l}\text { Umbul Tirto } \\
\text { Raharjo }\end{array}$ & 3.176 & 1.662 & 0.550 & 0.550 \\
\hline 12 & $\begin{array}{l}\text { Umbul } \\
\text { Manten }\end{array}$ & 2.518 & 0.979 & 1.426 & 0.979 \\
\hline 13 & $\begin{array}{l}\text { Umbul } \\
\text { Sigedang }\end{array}$ & 2.375 & 0.709 & 1.933 & 0.709 \\
\hline 14 & $\begin{array}{l}\text { Umbul } \\
\text { Jolotundo }\end{array}$ & 3.495 & 2.082 & 0.357 & 0.357 \\
\hline 15 & $\begin{array}{l}\text { Umbul Her } \\
\text { Pancuran } \\
\text { Sidomulyo }\end{array}$ & 0.439 & 1.589 & 3.190 & 0.439 \\
\hline 16 & $\begin{array}{l}\text { Umbul } \\
\text { Besuki }\end{array}$ & 0.150 & 1.870 & 3.413 & 0.150 \\
\hline 17 & $\begin{array}{l}\text { Umbul } \\
\text { Susuhan }\end{array}$ & 3.862 & 2.427 & 0.756 & 0.756 \\
\hline 18 & $\begin{array}{l}\text { Umbul } \\
\text { Kajen }\end{array}$ & 1.512 & 1.336 & 2.920 & 1.336 \\
\hline
\end{tabular}

Hasil yang peroleh pada perhitungan berhenti pada Iterasi ke 8 . dengan pusat cluster $\mathrm{C} 1$ : ( $1.275,1,1.025,1.025,1.775,1.2), \mathrm{C} 2$ : ( 2.483, 1.383, 1.566, 2.116, 2.216, 1.783 ) dan C3 : ( 2.562, 2.537, 2.687, 2.612, 2.877, 2.237)

Kesimpulan yang dapat diambil dari perhitungan pada tabel Iterasi ke 8 Cluster ke 1 memiliki nilai titik pusat cluster centroid $(1.275,1,1.025,1.025,1.775,1.2)$ Ada 4 umbul dengan kriteria Cukup, Cluster ke 2 memiliki nilai titik pusat cluster centroid (2.483, 1.383, 1.566, 2.116, 2.216, 1.783) Ada 6 umbul dengan kriteria Baik, Cluster ke 3 memiliki nilai titik pusat cluster centroid (2.562, 2.537, 2.687, 2.612, 2.877, 2.237) Ada 8 umbul dengan kriteria Sangat Baik.

\subsection{Implementasi}

Implementasi berisi paparan gambar asli dari sistem yang dikerjakan oleh penyusun dengan masalah menentukan dan memetakan objek wisata umbul Klaten sesuai dengan kategori, dan aplikasi ini nantinya akan digunakan untuk masyarakat dan wisatawan. Hasil dari implementasi program yang telah dibangun dapat terlihat seperti pada tampilan pada gambar berikut.

Halaman ini menampilkan data pengguna (admin) multi user. Tampilan halaman data pengguna ditunjukkan pada Gambar 1.

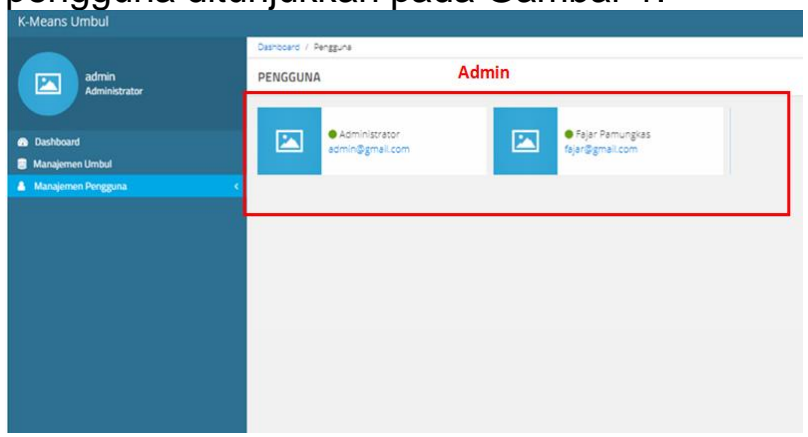

Gambar 1. Halaman data admin

Halaman manajemen umbul menampilkan dua menu yaitu Tambah Umbul dan Hitung $K$ means, serta menampilkan peta umbul dan Daftar Umbul.Halaman manajemen umbul ditunjukkan pada Gambar 2.

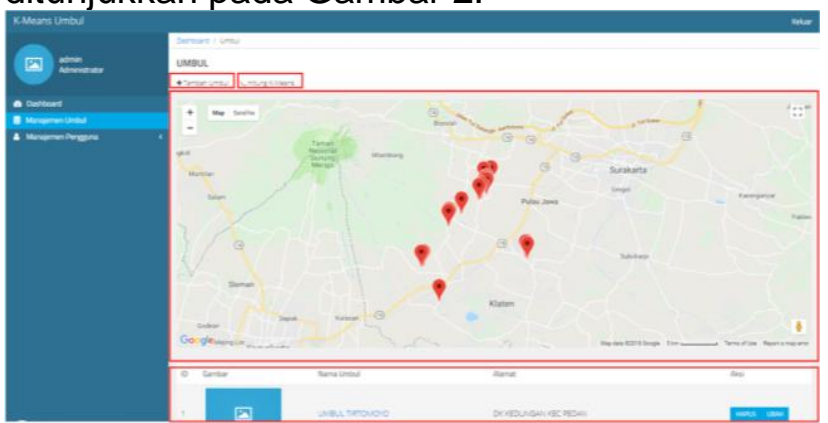

\section{Gambar 2. Halaman menejemen umbul}

Halaman ini menampilkan hitungan iterasi dan pusat clusternya. Sistem ini berhenti pada hitungan iterasi ke 8. Tampilan halaman hitungan K-Means ditunjukkan pada Gambar 3.

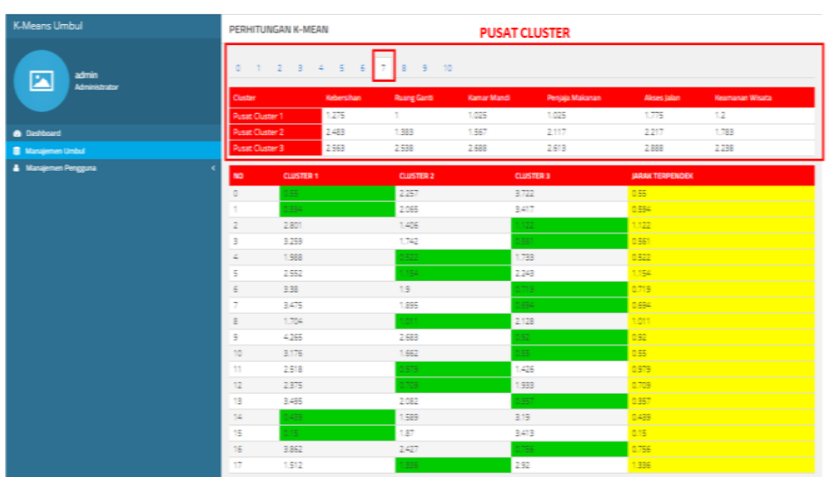

Gambar 3. Halaman hitung K-means

Halaman ini menampilkan data hasil akhir hitungan K-means clustering pada sistem pemetaan objek wisata umbul Klaten. Tampilan halaman hasil akhir di tunjukkan pada Gambar 4. 


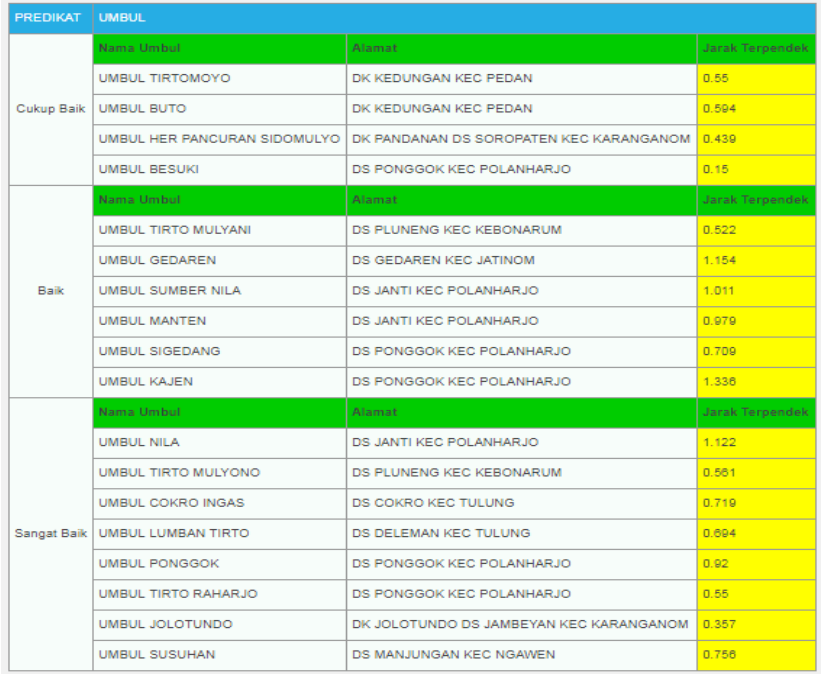

Gambar 4. Halaman hasil akhir

\subsection{Hasil Uji Sistem}

Sistem pemetaan objek wisata umbul ini telah diuji secara fungsional dan perbandingan sistem hitung dengan aplikasi Microsoft exel dari pengujian di dapatkan hasil bahwa fungsi sistem sesuai dengan fungsinya dan hasil perbandingan dari aplikasi Microsoft excel sama dengan sistem yang telah dibuat. Penjelasan dari fungsional sistem ditunjukkan pada Tabel 5.

Tabel 5. Uji fungsional

\begin{tabular}{|c|c|c|c|c|}
\hline No & $\begin{array}{c}\text { Komponen } \\
\text { yang diuji }\end{array}$ & Skenario Uji & $\begin{array}{l}\text { Hasil yang } \\
\text { diharapkan }\end{array}$ & $\begin{array}{c}\text { Hasil } \\
\text { Penguji }\end{array}$ \\
\hline 1 & $\begin{array}{l}\text { Login } \\
\text { Admin/User }\end{array}$ & $\begin{array}{l}\text { - Masukan } \\
\text { username dan } \\
\text { password } \\
\text { dengan benar } \\
\text { - Masukan } \\
\text { username dan } \\
\text { password } \\
\text { kosong } \\
\text { - Masukan } \\
\text { username } \\
\text { dengan benar } \\
\text { dan password } \\
\text { kosong. } \\
\text { Masukan } \\
\text { username dan } \\
\text { password } \\
\text { dengan salah }\end{array}$ & $\begin{array}{l}\text { - Tampil } \\
\text { halaman } \\
\text { utama } \\
\text { beranda } \\
\text { - Muncul } \\
\text { pesan } \\
\text { Muncul } \\
\text { pesan } \\
\text { "please fill out } \\
\text { this field" } \\
\text { pada kolom. } \\
\text { - Muncul } \\
\text { pesan } \\
\text { "please fill out } \\
\text { this field" } \\
\text { pada kolom } \\
\text { password. } \\
\text { Muncul } \\
\text { pesan "infalid } \\
\text { credential" }\end{array}$ & $\begin{array}{l}\text { - Hasil } \\
\text { Sesuai } \\
\text { - Hasil } \\
\text { Sesuai }\end{array}$ \\
\hline 2 & $\begin{array}{l}\text { Input } \\
\text { Tambah } \\
\text { Umbul }\end{array}$ & $\begin{array}{l}\text { Masuk menu } \\
\text { tambah umbul } \\
\text { Masukan data } \\
\text { daftar umbul } \\
\text { dengan lengkap } \\
\text { dan simpan. } \\
\text { - Masukan data } \\
\text { daftar umbul } \\
\text { dengan hanya } \\
\text { mengisi nama } \\
\text { dan alamat lalu } \\
\text { simpan. } \\
\text { Masukan data } \\
\text { daftar umbul } \\
\text { dengan hanya } \\
\text { mengisi kolom } \\
\text { latitude dan } \\
\text { longitude lalu } \\
\text { simpan. }\end{array}$ & $\begin{array}{l}\text { - Tampil } \\
\text { halaman } \\
\text { proses } \\
\text { tambah daftar } \\
\text { umbul } \\
\text { - Muncul } \\
\text { pesan } \\
\text { "berhasil } \\
\text { menambahka } \\
\text { n umbul baru" } \\
\text { - Muncul } \\
\text { pesan } \\
\text { "berhasil } \\
\text { menambahka } \\
\text { n umbul baru" } \\
\text { - Muncul } \\
\text { pesan } \\
\text { "please fill out } \\
\text { this field" } \\
\text { pada kolom } \\
\text { nama umbul }\end{array}$ & $\begin{array}{ll}- & \text { Hasil } \\
& \text { Sesuai } \\
\text { - } & \text { Hasil } \\
& \text { Sesuai }\end{array}$ \\
\hline 3 & $\begin{array}{l}\text { Edit Daftar } \\
\text { Umbul }\end{array}$ & $\begin{array}{l}\text { Pilih menu } \\
\text { "ubah" pada } \\
\text { daftar umbul } \\
\text { - Ubah daftar } \\
\text { umbul dengan } \\
\text { benar dan }\end{array}$ & $\begin{array}{l}\text { Tampil } \\
\text { halaman } \\
\text { proses edit } \\
\text { daftar umbul } \\
\text { - Muncul } \\
\text { pesan "1 }\end{array}$ & $\begin{array}{ll}- & \text { Hasil } \\
& \text { Sesuai } \\
\text { - } & \text { Hasil } \\
& \text { Sesuai }\end{array}$ \\
\hline
\end{tabular}

\begin{tabular}{|c|c|c|c|c|}
\hline No & $\begin{array}{c}\text { Komponen } \\
\text { yang diuji }\end{array}$ & Skenario Uji & $\begin{array}{c}\text { Hasil yang } \\
\text { diharapkan }\end{array}$ & $\begin{array}{c}\text { Hasil } \\
\text { Penguji }\end{array}$ \\
\hline & & simpan & $\begin{array}{l}\text { umbul } \\
\text { berhasil } \\
\text { diubah" }\end{array}$ & \\
\hline 4 & $\begin{array}{l}\text { Hapus Daftar } \\
\text { Umbul }\end{array}$ & $\begin{array}{l}\text { Pilih menu } \\
\text { "hapus" pada } \\
\text { daftar umbul }\end{array}$ & $\begin{array}{l}\text { Tampil } \\
\text { halaman } \\
\text { manajemen } \\
\text { umbul dan } \\
\text { umbul } \\
\text { berhasil } \\
\text { dihapus. } \\
\end{array}$ & $\begin{array}{ll}\text { - } & \text { Hasil } \\
& \text { Sesuai }\end{array}$ \\
\hline 5 & $\begin{array}{l}\text { Input Data } \\
\text { Survei Umbul }\end{array}$ & $\begin{array}{l}\text { - Pilih daftar } \\
\text { umbul dan pilih } \\
\text { menu "tambah } \\
\text { penilaian" } \\
\text { - Masukan nama } \\
\text { dan penilaian } \\
\text { dengan benar } \\
\text { lalu simpan } \\
\text { - Kosongkan } \\
\text { nama dan beri } \\
\text { penilaian } \\
\text { dengan benar } \\
\text { lalu simpan } \\
\text { - Masukan nama } \\
\text { dengan benar } \\
\text { dan kosongkan } \\
\text { penilaian, } \\
\text { simpan. }\end{array}$ & $\begin{array}{l}\text { Tampil } \\
\text { halaman } \\
\text { tambah } \\
\text { penilaian } \\
\text { data survey. } \\
\text { - Muncul } \\
\text { pesan } \\
\text { "penilaian } \\
\text { umbul } \\
\text { berhasil di } \\
\text { input" } \\
\text { "the nama } \\
\text { wisatawan } \\
\text { field is } \\
\text { required" } \\
\text { "the } \\
\text { penilaian field } \\
\text { is required" }\end{array}$ & $\begin{array}{ll}\text { - } & \text { Hasil } \\
& \text { Sesuai } \\
\text { - } & \text { Hasil } \\
& \text { Sesuai } \\
\text { - } & \text { Hasil } \\
& \text { Sesuai } \\
& \\
\text { - } & \text { Hasil } \\
& \text { Sesuai }\end{array}$ \\
\hline 6 & $\begin{array}{c}\text { Hitung } \\
\text { K-Means }\end{array}$ & $\begin{array}{l}\text { - } \begin{array}{l}\text { Pilih Normal } \\
\text { data }\end{array} \\
\text { - } \text { Pilih Iterasi } \\
\text { - Pilih Hasil Akhir }\end{array}$ & $\begin{array}{l}\text { - Tampil } \\
\text { halaman } \\
\text { proses } \\
\text { normal data } \\
\text { - Tampilan } \\
\text { proses Iterasi } \\
\text { sampai } \\
\text { selesai } \\
\text { - Tampilan } \\
\text { hasil akhir } \\
\end{array}$ & $\begin{array}{ll}\text { - } & \text { Hasil } \\
& \text { Sesuai } \\
\text { - } & \text { Hasil } \\
& \text { Sesuai } \\
\text { - } & \text { Hasil } \\
& \text { Sesuai }\end{array}$ \\
\hline 7 & $\begin{array}{l}\text { Input Data } \\
\text { Admin } \\
\text { /Pengguna }\end{array}$ & $\begin{array}{ll}\text { - } & \text { Pilih } \\
\text { manajemen } \\
\text { pengguna } \\
\text { - Pilih menu } \\
\text { "tambah" } \\
\\
\\
\text { - Masukan data } \\
\text { admin / } \\
\text { pengguna } \\
\text { dengan benar } \\
\text { lalu simpan. } \\
\text { - Masukan data } \\
\text { admin / } \\
\text { pengguna } \\
\text { dengan } \\
\text { mengosongkan } \\
\text { kolom atau tidak } \\
\text { lengkap, simpan }\end{array}$ & $\begin{array}{l}\text { - } \text { Muncul } \\
\text { halamann } \\
\text { admin/pengg } \\
\text { una } \\
\text { - Tampil } \\
\text { halaman } \\
\text { tambah } \\
\text { pengguna } \\
\text { untuk mengisi } \\
\text { kolom. } \\
\text { - Muncul } \\
\text { pesan } \\
\text { "Berhasil } \\
\text { menambahka } \\
\text { n pengguna } \\
\text { baru" } \\
\text { - Muncul } \\
\text { pesan } \\
\text { "please fill out } \\
\text { this field" } \\
\text { pada kolom } \\
\text { yang belum } \\
\text { di isi. } \\
\end{array}$ & $\begin{array}{ll}\text { - } & \text { Hasil } \\
\text { Sesuai } \\
\text { - } & \text { Hasil } \\
& \text { Sesuai } \\
& \\
\text { - } & \text { Hasil } \\
& \text { Sesuai } \\
\text { - } & \text { Hasil } \\
& \text { Sesuai }\end{array}$ \\
\hline 8 & $\begin{array}{l}\text { Edit Data } \\
\text { Admin } \\
\text { /Pengguna }\end{array}$ & $\begin{array}{l}\text { - Masuk data } \\
\text { admin// } \\
\text { pengguna } \\
\text { - Ubah data } \\
\text { admin/ } \\
\text { pengguna lalu } \\
\text { simpan }\end{array}$ & $\begin{array}{l}\text { - Muncul } \\
\text { halaman } \\
\text { admin/pengg } \\
\text { una } \\
\text { - Muncul } \\
\text { pesan } \\
\text { "berhasil } \\
\text { mengubah } \\
\text { admin// } \\
\text { pengguna" }\end{array}$ & $\begin{array}{ll}\text { - } & \text { Hasil } \\
& \text { Sesuai } \\
\text { - } & \text { Hasil } \\
& \text { Sesuai }\end{array}$ \\
\hline 9 & $\begin{array}{l}\text { Hapus Data } \\
\text { Admin / } \\
\text { Pengguna }\end{array}$ & $\begin{array}{l}\text { - Pilih data } \\
\text { admin/ } \\
\text { pengguna yang } \\
\text { akan dihapus }\end{array}$ & $\begin{array}{l}\text { Muncul } \\
\text { pesan } \\
\text { "berhasil } \\
\text { menghapus } \\
\text { admin/ } \\
\text { pengguna" } \\
\text { dan kembali } \\
\text { ke halaman } \\
\text { pengguna. }\end{array}$ & $\begin{array}{ll}\text { - } & \text { Hasil } \\
& \text { Sesuai }\end{array}$ \\
\hline
\end{tabular}

Berdasarkan uji fungsional pada Tabel 5 menunjukan sistem yang telah dibuat bebas dari kesalahan dan secara fungsional menggeluarkan hasil yang sesuai yang diharapkan, dibuktikan dengan pengujian blackbox. 


\section{PENUTUP}

\subsection{Kesimpulan}

Berdasarkan hasil analisis dan pengolahan data yang ada maka dapat diambil kesimpulan sebagai berikut:

1. Telah terbangunnya Sistem Pemetaan Objek Wisata Umbul Klaten guna membantu masyarakat dan wisatawan mendapatkan informasi tentang kelayakan objek wisata umbul dan mengetahui kategori setiap objek wisata umbul apakah tergolong dalam kategori Cukup, Baik atau Sangat Baik. Terdapat 4 umbul yang termasuk dalam kategori Cukup yaitu umbul Tirtomoyo, umbul Buto, umbul Pancuran, dan umbul Besuki. Kategori Baik meliputi umbul Tirto Mulyani, Gedaren, Sumber Nila, Manten, Sigedang, dan Kajen. Kategori Sangat Baik meliputi umbul Nila, Tirto Mulyono, Ingas, Lumban Tirto, Ponggok, Tirto Raharjo, Jolotundo, dan Susuhan.

2. Pada uji fungsionalitas sistem dengan metode blackbox, Sistem Pemetaan Objek Wisata Umbul Klaten bebas dari kesalahan sintaks dan secara fungsional mengeluarkan hasil yang sesuai dengan apa yang di harapkan.

\subsection{Saran}

1. Sistem Pemetaan Objek Wisata Umbul perlu segera direalisasikan secara langsung agar bisa dimanfaatkan oleh calon wisatawan. Selain itu agar dapat diketahui dimana letak kekurangan aplikasi ini yang belum sesuai dengan pencatatan di lapangan guna pengembangan sistem selanjutnya.

2. Penginputan data survei disarankan selalu rutin dilakukan pembaharuan maksimal 1 tahun sekali agar data yang dihasilkan selalu up to date.

3. Pengembangan sistem kedepan, dapat dilakukan penambahan penilaian atribut agar mendapatkan data yang lebih lengkap seperti harga tiket masuk, tempat parkir, fasilitas sewa alat renang, dan tingkat kepuasan pengunjung.

\section{DAFTAR PUSTAKA}

[1] H. Kamber, "Data Mining Concepts and Techniques." Canada: Morgan Kaufmann, 2011.

[2] Hartatik, "Pengelompokan Mahasiswa Berdasarkan Nilai Ujian Nasional Dan Ipk Menggunakan Metode K-Means," Pros. Semin. Nas. Inform., pp. 35-40,
2014.

[3] F. Nasari and S. Darma, Penerapan KMeans Clustering Pada Data Penerimaan Mahasiswa Baru (Studi Kasus: Universitas Potensi Utama), Seminar Nasional Teknologi Informasi dan Multimedia, pp. 6-8, 2015.

[4] F. A. Syam, "Implementasi Metode Klastering K-Means Untuk Mengelompokan Hasil Evaluasi Mahasiswa," IImu Komput. dan Bisnis, vol. 8, no. Sunjana 2010, pp. 18411846, 2017.

[5] P. Eko, Data Mining - Konsep dan Aplikasi Menggunakan MATLAB. Yogyakarta: Penerbit Andi, 2012.

[6] N. Rohmawati, S. Defiyanti, and M. Jajuli, "Implementasi Algoritma K-Means Dalam Pengklasteran Mahasiswa Pelamar Beasiswa," J. IIm. Teknol. Inf. Terap., vol. I, no. 2, pp. 62-68, 2015.

[7] R.S Pressman, Rekayasa Perangkat Lunak (Pendekatan Praktisi) Edisi 7 Buku 1. Yogyakarta: Penerbit Andi, 2012. 